

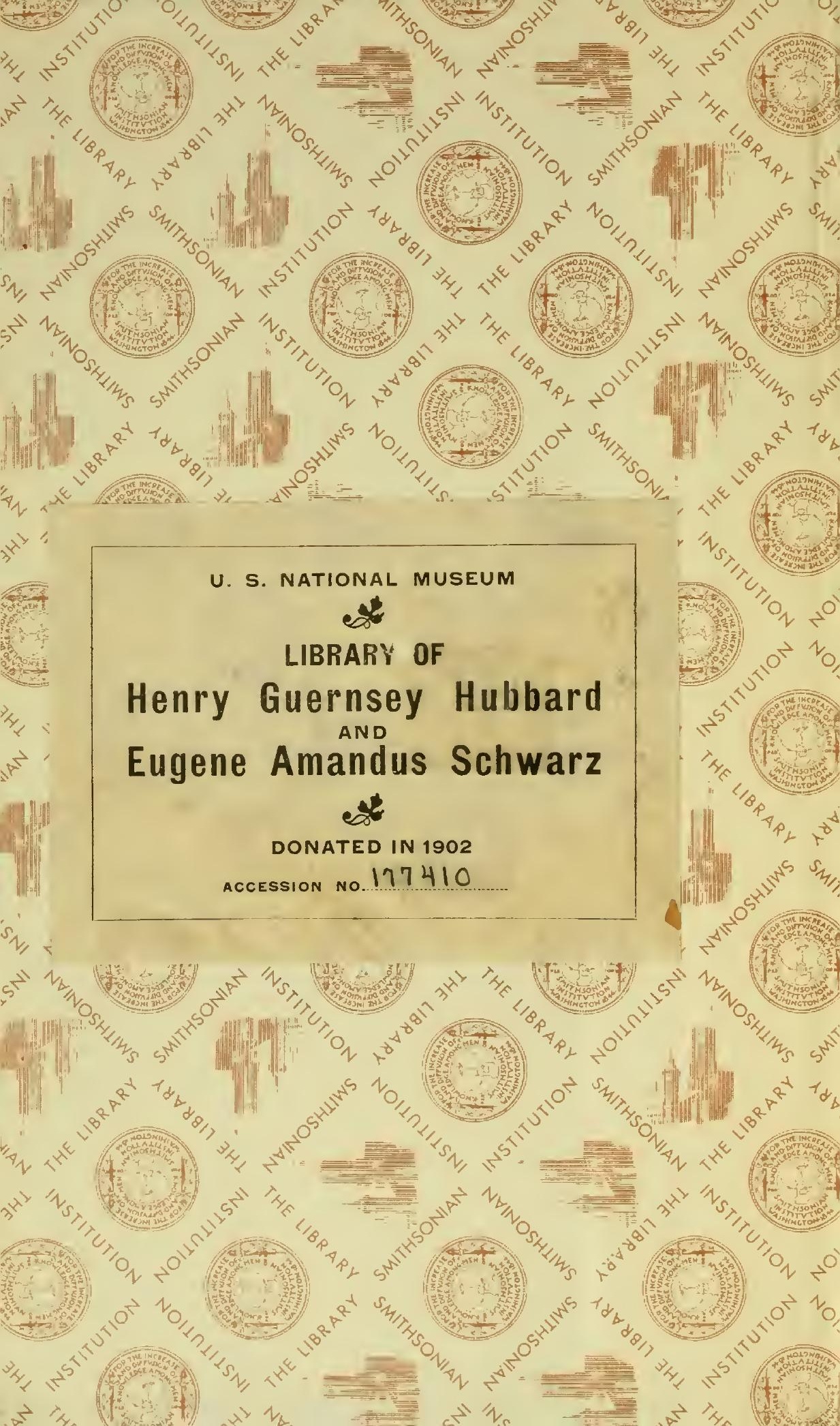



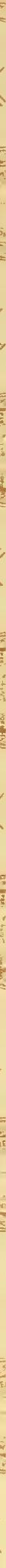





\section{PROCEEDINGS}

OF THE

\section{AMERICAN PHILOSOPHICAL SOCIETY}

HELD AT PIIILADELPHIA

FOR

\section{PROMOTING USEFUL KNOWLEDGE}

Vol. XV.

DECEMBER $18 \% 6$.

No. 96 .

PHILA DELPHIA :

PRINTED FOR THE SOCIETY

BY M'CALLA \& STAVELY.

1876. 

ân:"

'He American Journal of Science and ARts, Vol. XLIV, Jui, 1867.7

ON THE

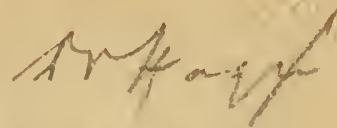

\title{
SYSTEMATIC VALUE OF RHYNCHOPHOROUS COLEOPTERA.
}

\begin{abstract}
An Abstract of a Memoir read before the National Academy of Sciences, at Washington, Jan. 24th, 1867.
\end{abstract}

\section{BY JOHN L. LECONTE.}

In the empirical arrangement of the families of Coleoptera, which has resulted from the adoption of the tarsal system of division, the families contained in the great natural group of Heteromera are followed by the Curculionidæ and Scolytidæ, which, more or less subdivided into smaller families, have been supposed to establish a linear relation betiveen the rostrated Heteromera (Salpingus, Rhinosimus, \&c.) to the Cerambycidæ and Chrysomelidæ, the great types of the Pseudotetramera, or Subpentamera, of various authors.

It is the object of the present investigation to determine the limits, and the relations of the first mentioned of these types, the Rhynchophora.

The inferiority of this type is manifested, not only in the larval condition by the limited number or absence of visual lenses, the want of locomotive appendages, the feeble development or entire want of antennæ, and the unchitinized epidermis; but also by the combination in the imago of characters belonging to a perfectly developed organism with others pertaining to an inferior grade in the scale of Coleoptera.

Thus, for instance, while we perceive in the other series of beetles, that the lower forms retain certain larval characters, as evidenced by the extension of the coxæ, the imperfection of the anterior coxal cavities, the softness of the integuments, and the want of centralization in the abdomen, all such degradational characters are absent in the Rhynchophora.

Other characters representing low grades in their respective series do not appear in the Rhynchophora, such as vegetative growth of the organs of sense, indicated by pectinate or flabellate antennæ, or excessive length of palpi.

On the contrary, we find in the Rhynchophora, that the integuments are perfectly chitinized: the elytra never abbreviated or wanting; the anterior coxæ are always completely enclosed; the ventral segments, usually five, never exceed six in number.

The plan of degradation, in passing from the higher to the lower forms, is by the extension of the longitudinal axis of the body, in its anterior half; this is usually most strongly manifested in the head, and exhibited not only by the length of the beak, but by the conformation of the lower floor of the mouth. 
Commencing with those Curculionidæ (Adelognathi Lacordaire, in which the mentum fills the gular emargination, as in the higher Tenebrionidx, we find a gradual lessening in size of the mentum, itself becoming supported upon a broad, short, gular peduncle, permitting the maxillæe to become visible, (Phanerognathi, Cohort 1, Lacordaire): next the gular peduncle becomes elongated, and bilobed, receiving the mentum, now reduced to very small size, between its lobes (Phanerognathi, Cohort 11, and also Brenthidæ, and Anthribidæ).

Having in the continuance of my work on the Classification of Coleoptera of North America, recently commenced a critical study of our Rhynchophora, I became aware of the impossibility of intercalating them between the Heteromera and Subpentamera, and am now convinced that they represent a special type, which must be isolated from all other types of Coleoptera, pos. sessing a systematic value equal to all the others combined.

In seeking for the characters which should define this type, I observed a remarkable difference in the arrangement of the pieces of the under surface of the prothorax, heretofore overlooked, and so far as I know, confined to this particular type.

In other Coleoptera, the prosternum is either extended behind the anterior coxæ, so as to form part of the hind margin of the segment, thus coming in contact with the mesosteruum, or it is cut off between the coxæ, and in this case (as in many others) the coxal cavities are open behind: in the few exceptions (Derodontus, Dacoderus) in which the coxæ are contiguous and the cavities closed behind, the prosternum still extends behind the coxæ, to the hind margin of the segment, as is shown by the short sutures separating the epimera from the medial piece of the prosternum.

I have represented these modifications of form in the adjoin-

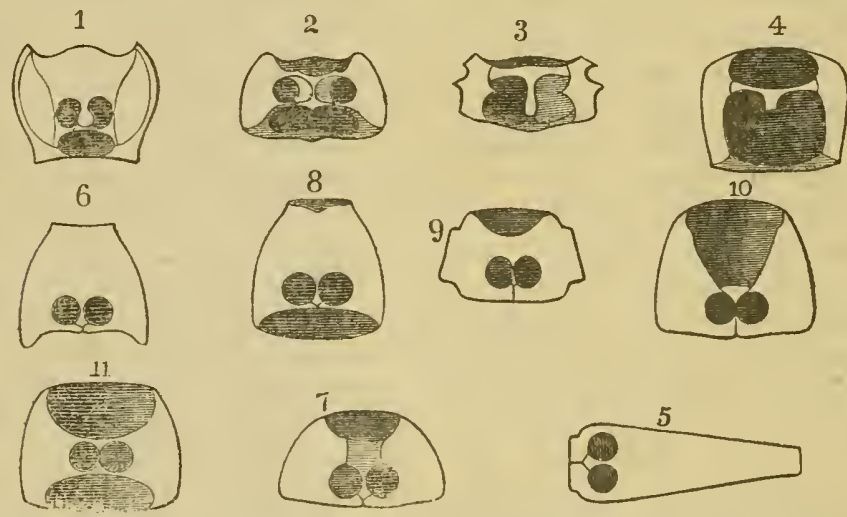

ing wood-cuts. Fig. 1, under surface of prothorax of a Carabide (Pasimachus); the coxal cavities are closed, and the epimera an- 
episterna well defined. Fig. 2, do. of a Scarabæide (Lachnosterna): the coxæ are transverse, the cavities closed, the side pieces not distinct. Fig. 3, do. of Cucujus ; coxal cavities open behind, side pieces not distinct. Fig. 4, do. of Telephorus: coxal cavities confluent and open behind.

In Rhynchophora the prothoracic sutures are obliterated, there is no separation between the prosternum and episterna, and very rarely between the latter and the pronotum: the coxal cavities, frequently confluent, are always closed behind, by the epimera, which become connate on the median line, enclosing the hind part of the prosternum, thus cutting it off completely from the mesothoracic segment.

Fig. 5 represents this arrangement of parts in a Brenthide, in which family the extreme limit of degradation by linear extension is reached. Fig. 6, under surface of prothorax of a Calandride (Rhynchophorus). Fig. 7, do. of Cryptorhynchus. Fig. 8, do. of Balaninus. Fig. 9, do. Ophryastes. Fig. 10, do. Thecesternus. Fig. 11, do. Dendroctonus.

When the coxæ are contiguous, the point of the prosternum is visible behind them, but is none the less perfectly enclosed by the growth of the side pieces to the median line.

Another evidence of the inferiority of type of the Rhynchophora, which has not been mentioned, is seen in the functions performed by the beak, which in the lower groups, especially in the female, becomes greatly elongated. The occurrence of corneous exserted ovipositors in other orders of insects is not rare: a few species of Coleoptera (certain Valgus, for example) have the last abdominal segment prolonged, simulating such an organ. But it was reserved for the Rhynchophora to exhibit a degradation of type, by which a function, peculiarly appropriate to the posterior extremity of the body, is performed by the head : the elongated beak becoming in fact the ovipositor.

Thus the inferiority of grade, evidenced in other series of Coleoptera by the softness of the integuments, or by the permanence of larval forms, chiefly in the abdomen and c(Ixæ, is in the Rhynchophora manifested by the transfer of a function from the posterior to the anterior part of the body, and the linear extension of the latter, in accordance with this 'change of base.'

The principles of classification of Rhynchophora, and their division into families will be discussed in a subsequent memoir. It is, however, proper to observe that the peculiar construction of prothorax above described as characteristic of the Rhynchophora, is not exhibited in the Bruchidæ, which family, as observed by Lacordaire (Gen. Col. vii, 600), should be viewed as closely related to, if not actually a portion of, the great family Chrysomelidæ. 











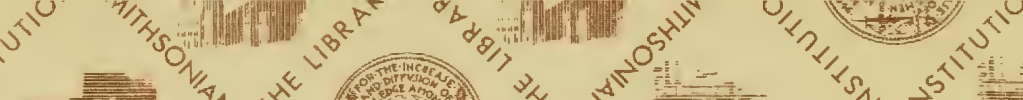

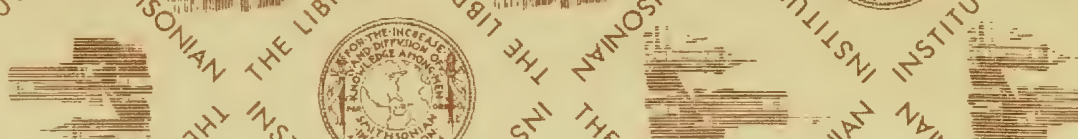

$3 / \mathrm{S}^{2}$

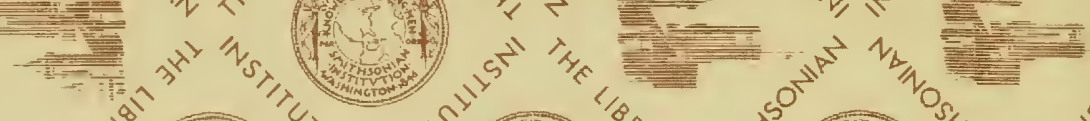

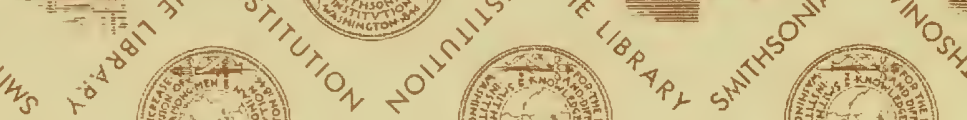

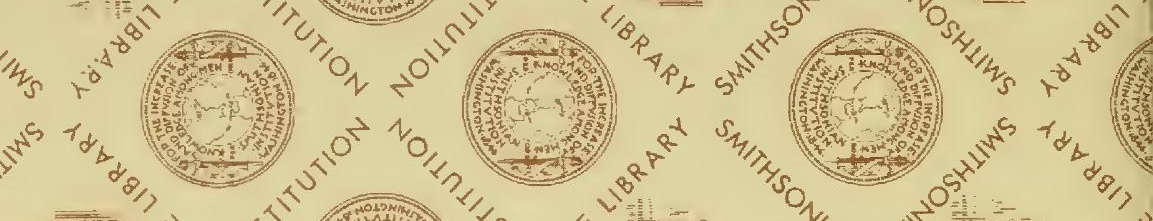

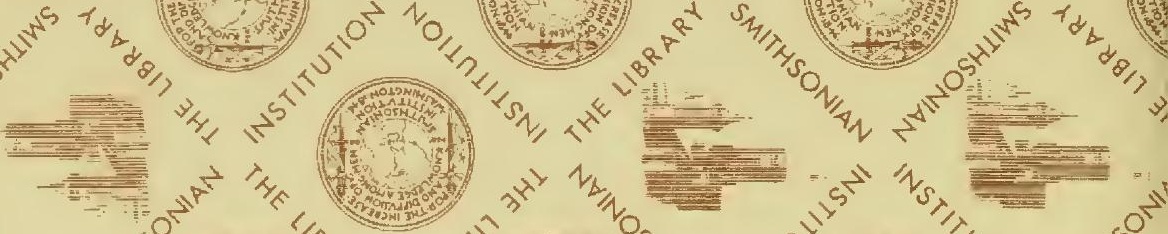

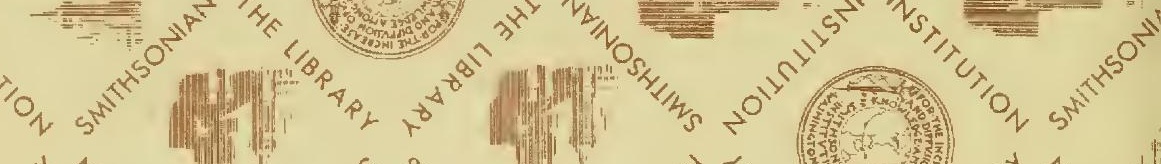

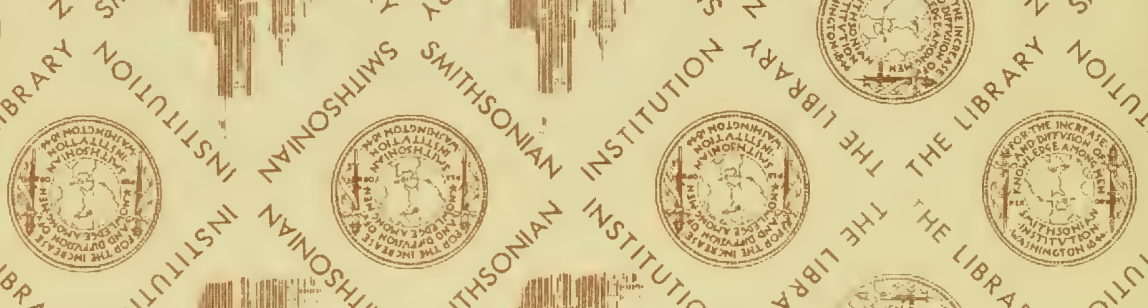

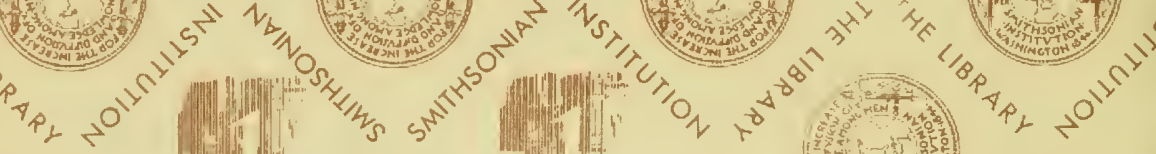

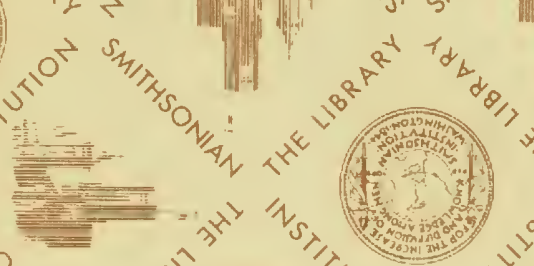

$0^{5}$
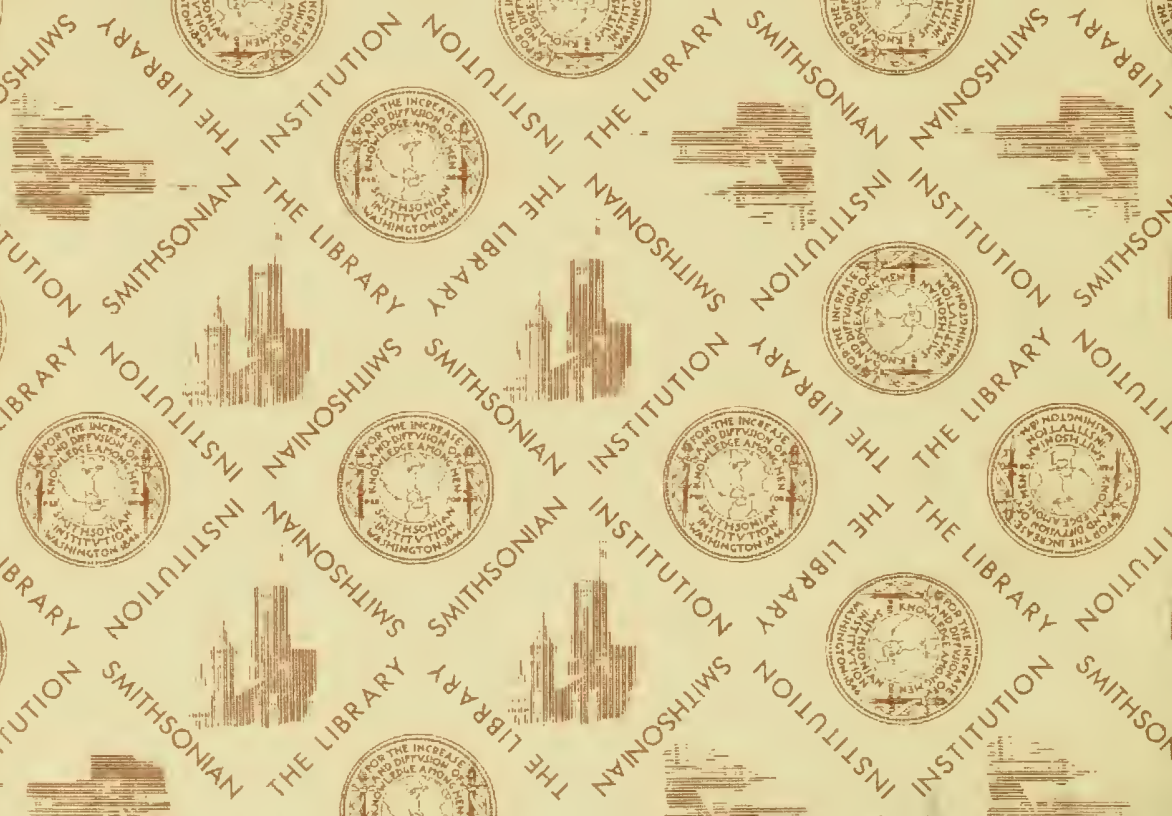


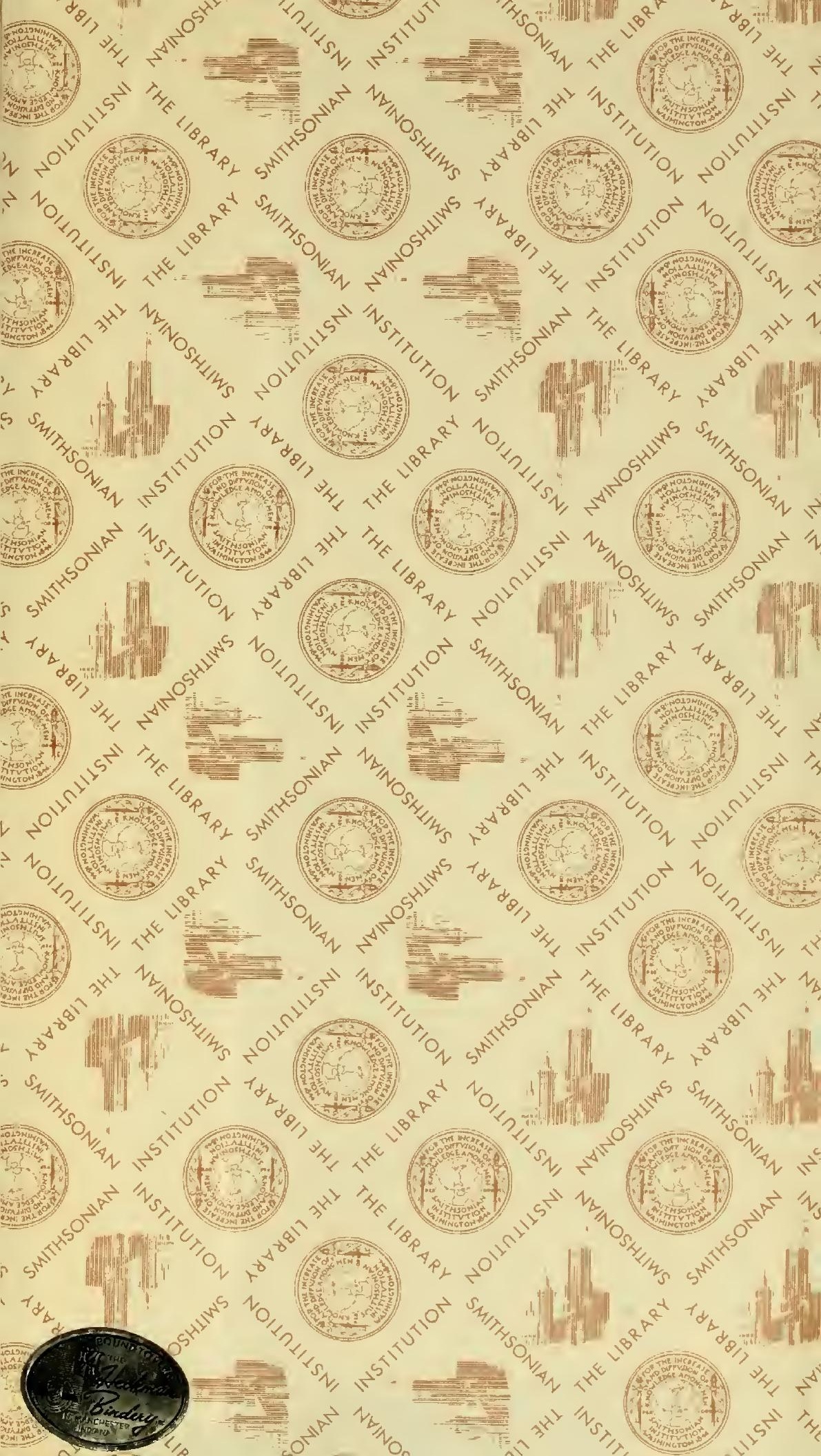


SMITHSONIAN INSTITUTION LIBRARIES 